Working Paper/Document de travail 2015-33

\title{
Cheap But Flighty: How Global Imbalances Create Financial Fragility
}

by Toni Ahnert and Enrico Perotti 
Bank of Canada Working Paper 2015-33

August 2015

\title{
Cheap But Flighty: How Global Imbalances Create Financial Fragility
}

by

\author{
Toni Ahnert ${ }^{1}$ and Enrico Perotti ${ }^{2}$ \\ 1Financial Stability Department \\ Bank of Canada \\ Ottawa, Ontario, Canada K1A 0G9 \\ tahnert@bankofcanada.ca \\ ${ }^{2}$ Amsterdam Business School \\ University of Amsterdam \\ E.C.Perotti@uva.nl
}

Bank of Canada working papers are theoretical or empirical works-in-progress on subjects in economics and finance. The views expressed in this paper are those of the authors. No responsibility for them should be attributed to the Bank of Canada. 


\section{Acknowledgements}

We thank Jason Allen, Fernando Broner, Nicola Gennaioli, Christopher Hajzler, Olivier Jeanne, Alberto Martin, Josef Schroth, Javier Suarez and seminar participants at UvA Amsterdam, Bank of Canada, Bank of England, CEMFI, the CEPR-IESE Conference on Financial Stability and Regulation, the CEPR-CREI Workshop on Macroeconomics of Global Interdependence, Financial Intermediation Research Society Meeting, IMF, New York Federal Reserve and NYU for useful comments. 


\begin{abstract}
We analyze how a wealth shift to emerging countries may lead to instability in developed countries. Investors exposed to expropriation risk are willing to pay a safety premium to invest in countries with good property rights. Domestic intermediaries compete for such cheap funding by carving out safe claims, which requires demandable debt. While foreign inflows allow countries to expand their domestic credit, risk-intolerant foreign investors withdraw even under minimal uncertainty. We show that more foreign funding causes larger and more frequent runs. Beyond some scale, even risk-tolerant domestic investors are induced to withdraw to avoid dilution. As excess liquidation causes social losses, a domestic planner may seek prudential measures on the scale of foreign inflows.
\end{abstract}

JEL classification: F3, G2

Bank classification: Financial stability; Financial institutions

\title{
Résumé
}

Un transfert de richesse vers les pays émergents peut conduire à de l'instabilité dans les pays développés. Les investisseurs qui sont exposés à un risque d'expropriation sont disposés à verser une prime de sécurité pour investir dans des pays où les droits de propriété sont bien établis. Les intermédiaires se font concurrence pour accéder à ce financement bon marché en structurant des créances sûres qui offrent aux investisseurs une dette exigible. Ces entrées de capitaux motivées par la recherche de sûreté permettent certes aux pays développés d'élargir leur crédit intérieur, mais les investisseurs étrangers réfractaires au risque retirent leurs placements même quand l'incertitude est minime. Un accroissement du financement de sources étrangères a pour effet d'augmenter la fréquence et l'importance des retraits massifs. Étant donné qu'une liquidation excessive se traduit par des pertes sur le plan social, un planificateur national pourrait envisager l'adoption de mesures prudentielles visant à limiter l'ampleur des entrées de capitaux étrangers.

Classification JEL : F3, G2

Classification de la Banque : Stabilité financière; Institutions financières 


\section{Non-Technical Summary}

This paper offers a rigorous foundation for the widespread view that global imbalances shaped the credit boom and, ultimately, the financial crisis. The recycling of large global imbalances in the form of safety-seeking inflows in the US financial system certainly boosted US credit creation. But how do such inflows affect financial stability?

In our model, investors differ in their exposure to expropriation risk. Countries with a weak protection of property rights have limited access to safe assets. This leads to capital flows seeking safe claims provided by intermediaries in safe countries. We show that the optimal contractual arrangement involves intermediaries that target cheap demandable debt claims issued to foreign investors, while domestic investors offer insurance in bad states. However, risk-intolerant foreign investors withdraw in uncertain states, forcing liquidation in some good states. Safety-seeking foreign funding is therefore cheap but flighty. The safety premium paid by foreign investors allows countries to expand domestic credit to marginal projects, which would have negative net present value at domestic discount rates.

Our main observation is that the safety-seeking nature of foreign flows creates risk. The demand for absolute safety not only redistributes risk among investors, but it also increases risk through larger and more frequent runs. This funding shift leads to greater vulnerability even in solvent states. An increasing scale of foreign funding may induce runs even by risk-tolerant investors since they seek to avoid dilution.

Our conclusions are consistent with recent empirical evidence on the global demand for safety and the induced expansion in short-term financial debt. The model also explains the empirical evidence for an increase in maturity transformation and credit volume in response to capital inflows. This result has clear policy implications and supports a mandate for introducing a macroprudential regulator to oversee the nature of foreign inflows because the socially preferred funding structure would involve less credit volume and more stability than the private choice. 


\section{Introduction}

The scale of the recent financial crisis has led to a search for global explanations. An influential view is that excess credit was driven by low interest rates, associated with the recycling of large global imbalances into the US financial system (Bernanke, 2005; Caballero et al., 2008; Merrouche and Nier, 2014), which compensated for low US saving rates. While capital has historically moved from developed to emerging countries to pursue higher returns, these flows fell short of the amount implied by neoclassical theory (Lucas, 1990). A common explanation is that expropriation risk in emerging countries associated with a weak institutional framework caused sudden reversals, leading to crises.

Since net capital flows reversed in 1998 (Prasad et al., 2007), emerging countries have invested much of their trade surpluses in safe assets in developed countries (Mendoza et al. 2009: Gourinchas and Rey, 2007). Foreign holdings represent approximately 20 per cent of US debt securities and over 50 per cent of the Treasury market. The private sector accounts for around 80 per cent by 2007 (Forbes, 2010). Because this demand for safety grew faster than US public debt, US intermediaries issued more safe private liabilities. This global portfolio reallocation boosted US credit volume and the concentration in risky holdings by US residents and intermediaries. Selling riskless assets to foreign investors led to an increase in the effective leverage of US financial institutions (Caballero and Krishnamurthy, 2009). Even as many US intermediaries suffered major outflows in 2007-08, the dollar appreciated because investors shifted to other dollar assets (Maggiori, 2013).

The literature has so far treated foreign capital inflows as inherently stable. In this paper, we study how a wealth shift to emerging countries increases capital flows and how these affect the funding structure, investment level and fragility of intermediaries in developed countries. Capital inflows are beneficial because they support higher domestic lending, but safety-seeking inflows increase the frequency and scale of runs on domestic intermediaries. As a result, safety-seeking inflows generate fragility and inefficient liquidation of investment. 
In our model, all investors have some demand for safety to ensure a subsistence level of consumption. Therefore, some amount of wealth has to be absolutely safe. Domestic and foreign investors only differ in terms of access to safety. As a result of expropriation risk, foreign investors access safe assets through intermediaries from countries with good protection of property rights. Since absolute safety requires demandable debt, more foreign funding results in a less stable funding structure. We show that, in equilibrium, both the volume of credit and aggregate risk increases in the amount of foreign funding. These results obtain in a simple optimal contracting setup without deposit insurance and bailouts, where intermediaries bear all the risk created by their choices.

The privately optimal funding arrangement of domestic intermediaries induces selfselection. Foreign investors accept the lower return of demandable debt in exchange for safety, while domestic investors not exposed to expropriation risk are willing to offer insurance by investing in a long-term debt claim 1 A key mechanism is that foreign investors choose to run whenever there is even minimal interim uncertainty, forcing excess liquidation of investment. Thus the risk intolerance of foreign investors not only concentrates risk on domestic investors in the low state (Caballero and Krishnamurthy, 2009), but it also increases fragility in some high states. In short, foreign funding is cheap but flighty.

Long-term funding would be desirable to prevent inefficient liquidation. But foreign investors would not accept such a claim because it is not perfectly safe even when it is senior to all other claims. Intermediaries that cannot commit ex ante to a liquidation policy prefer to continue investment in case of interim uncertainty. Therefore, risk-intolerant foreigners invest only if they have the right to withdraw in uncertain states, provided enough lossabsorbing funding is available to ensure safe withdrawals. This may produce massive runs even if only a few intermediaries face interim uncertainty and if there is low correlation across asset values. We also show that there may also be insufficient incentives for domestic arbitrageurs to prevent inefficient liquidation, especially when foreign funding is abundant.

1 Gourinchas et al. (2010) show that the United States provides insurance to the rest of the world in the form of a lower yield during normal times and a transfer of wealth to foreign investors in crisis. 
More lending may also have a direct effect on instability. Even if asset risk were constant, more credit may increasingly involve more opaque assets, defined as those with a slower resolution of uncertainty ${ }^{2}$ More interim uncertainty induces more frequent inefficient runs. Ultimately, both the scale and frequency of runs increase in the scale of safety-seeking foreign inflows.

These results suggest a welfare trade-off associated with foreign inflows. Cheap funding boosts domestic credit, enabling investment in marginal projects with a negative net present value (NPV) at domestic rates, subsidized by the safety premium earned from foreign investors. While the larger scale of lending is efficient in the baseline model, when excess liquidation leads to social costs, the socially optimal balance between stability and investment differs from the private choice. Our results provide a rationale for macroprudential policies that target short-term foreign inflows, such as a systemic risk tax on non-core funding (Shin, 2011; Hahm et al. 2013), to complement the capital and liquidity requirements proposed in Basel III $3^{3}$

When some domestic investors also hold demandable debt (because of liquidity needs, for example), they would not run under modest uncertainty because their safety needs are satisfied. However, once foreign funding reaches a certain scale, even risk-tolerant investors are motivated to run to avoid dilution caused by a foreign run.

Such a strong demand for safety may promote the creation of "safe intermediaries" that could overcome runs by investing only in safe assets funded by issuing long-term debt. However, because leveraged intermediaries have an incentive to invest in risky assets, they cannot credibly commit to providing absolute safety under even minimal uncertainty about asset choice. Kacperczyk and Schnabl (2013) document a similar risk-taking behaviour of "safe" money market mutual funds during the financial crisis.

\footnotetext{
${ }^{2} \mathrm{~A}$ recent example is securitized mortgages pools that are relatively safe but hard to evaluate. Jorda et al. (2014) document the role of housing finance in large credit booms followed by crises.

JIn this context, public guarantees would allow banks to attract more unstable funding, shifting both exogenous and endogenous risk to public insurance.
} 
Discussion and Related Literature. Our model is driven by strong but simple assumptions and has clear limitations. Since it focuses on safety-seeking capital flows, it drastically simplifies the portfolio choice of investors. By construction, foreign investors who gained safety invest any residual wealth in their country, where the expected returns are higher. We also assume that high expropriation risk discourages domestic speculative outflows. While neither assumption is essential to our result, a more complete treatment of international portfolio choice is beyond the scope of our paper.

Our key assumption is that foreign investors need an intermediary to invest in domestic assets (Caballero and Krishnamurthy, 2009), which seems realistic. Intermediation may be indispensable for access, for safe-keeping (for investors subject to expropriation risk, even direct holdings need to be protected), or for anonymity when it is needed to avoid taxation or expropriation risk.

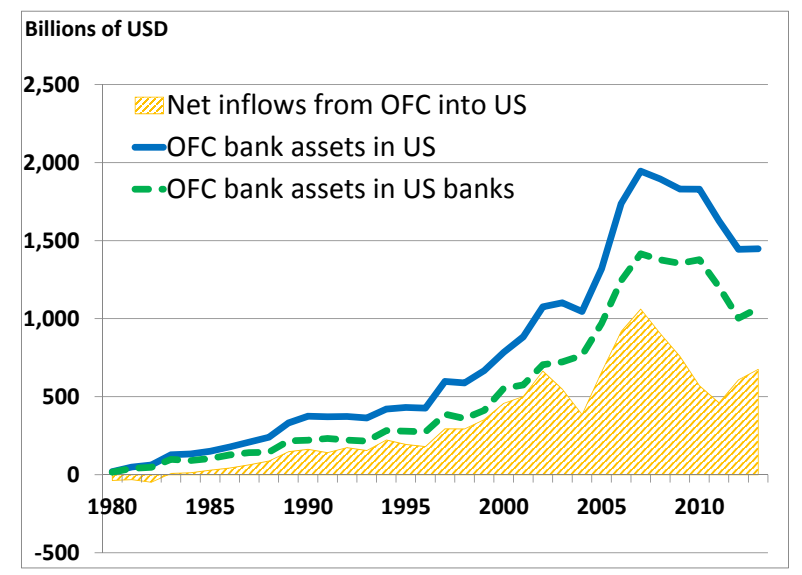

Figure 1: Flows between offshore financial centres (OFC) and the United States (US). Source: BIS locational banking statistics. All values in billions of US dollars (USD).

The accumulation of US deficits suggests a substantial buildup in the stock of foreign capital in excess of recorded official reserves. More granular evidence is impaired by a preference for anonymity, corroborated by the large flows channeled through legal entities in offshore financial centres (OFC). Figure 1 shows large net OFC inflows into the United States, targeted to privately intermediated safe assets. While foreign inflows into the US 
Treasury market are dominated by official institutions, OFC inflows into US intermediaries, estimated by the Federal Reserve System at $\$ 1.9$ trillion in 2014, represent over 40 per cent of foreign claims on US banks, dwarfing inflows from international financial centres (London, Hong Kong and Singapore) or rich economies (euro zone and Japan).

In our approach, a demand for safety arises from the large disutility when wealth falls short of some essential needs. While we do not claim that all foreign flows are unstable, our approach focuses on those safety-seeking inflows aimed at creating worst-case scenario reserves. Under Stone-Geary preferences, commonly used in development economics, utility is not defined below a subsistence level. A dynamic version of such preferences is used in habit formation models of asset pricing (Campbell and Cochrane, 1999). These preferences are consistent with the recent evidence on the strength and stability of demand for safe assets (Krishnamurthy and Vissing-Jorgensen, 2012; Gorton et al., 2012). Recent work has explained the demand for safety as arising from a subset of investors who are always infinitely risk-averse (Caballero and Farhi, 2013). In the presence of neglected risk, these preferences can create large-scale instability (Gennaioli et al., 2013).

Demandable debt is often explained by contingent liquidity demand with extreme time preferences (Diamond and Dybvig, 1983). In our model, demandable debt arises as an optimal contract to satisfy a demand for absolute safety. This is in the spirit of Gorton and Pennacchi (1990), who focus on adverse selection at the time of withdrawal. Demandable debt is also rationalized as an optimal contract to resolve agency conflicts (Diamond and Rajan, 2001; Calomiris and Kahn, 1991). In Diamond and Rajan (2001), demandable debt acts as a threat to control the banker. The presence of risk-avoiding investors would make such a threat quite costly since runs occur also in solvent states.

Our conclusions are consistent with recent empirical evidence. Krishnamurthy and Vissing-Jorgensen (2013) show how changes in the supply of government safe assets affect the safety premium and lead to a response in short-term financial debt. To satisfy the non-financial sector's demand net of public debt, the financial sector issues safe assets and 
increases long-term investments net of long-term funding. A strong demand for safety is associated with an increase in private credit and maturity transformation, as in our model.

There is abundant evidence of a large demand for safety. Foreign investors seeking safety accept lower rates of return (Caballero et al. 2008). Forbes (2010) finds that foreign investors with less developed domestic bond markets invest comparatively more in the United States, and they appear to earn lower returns than US investors earn abroad, even after adjusting for exchange rate movements. New evidence links political risk in specific countries to capital flight into safe havens (Badarinza and Ramadorai, 2015).

The notion of a strict segmentation between savings and speculative demand is increasingly common in the literature as a plausible foundation for bank funding preferences (Allen et al., 2015). The traditional view was based on a non-contingent liquidity preference for transaction purposes, the classic "money in the utility function" approach. Because money-like claims offer a convenience yield, they are cheaper to issue (Stein, 2012). This private incentive to offer liquid claims needs to be balanced against any illiquidity externality, such as fire sales (Perotti and Suarez, 2011; Stein, 2012). In our model, demandable debt arises from risk intolerance of safety-seeking foreign investors, rather than liquidity demand.

Finally, we contribute to the nascent literature on outflows from developing countries. Caballero et al. (2008) explain such flows as seeking improved intertemporal smoothing in countries with better financial development. Mendoza et al. (2009) show how countries with better private contractual enforcement offer better insurance for foreign investors. Our complementary approach highlights differences in expropriation risk and focuses on capital outflows that seek absolute safety. Quadrini (2015) offers a general equilibrium model where safety-seeking outflows increase intermediary leverage. In his approach, this may undermine the ability of firms to take risk, and thus cause large recessions in response to shocks.

The next section presents the basic model. We extend the results in several directions by introducing induced runs, excess risk correlation, endogenous asset opaqueness, private arbitrageurs and safe intermediaries. All proofs are in the appendices. 


\section{Model}

There are three dates, $t \in\{0,1,2\}$, and a domestic and foreign region. Domestic investors of mass 1 and foreign investors of mass $W$ have identical preferences, information and endowment $e$ at $t=0$. Preferences include a demand for absolute safety over a minimum consumption level $S \in(0,1)$, below which investors suffer a huge disutility. Once the subsistence level is secured, investors are risk-neutral with no time preference:

$$
U\left(c_{1}, c_{2}\right)=\left\{\begin{array}{lll}
c_{1}+c_{2} & & c_{1}+c_{2} \geq S \\
& \text { if } & \\
-\infty & & c_{1}+c_{2}<S
\end{array}\right.
$$

where $c_{t}$ denotes consumption at date $t$.

Investors can invest directly in physical storage and local financial assets, namely claims on intermediaries and government bonds. In both regions, storage yields a return of $x \in\left[\frac{S}{e}, 1\right)$, while short-term and long-term government bonds offer an unit return at $t=1$ and $T>1$ at $t=2$, respectively. Foreign investors require an intermediary to access domestic assets 4 Initially, intermediaries invest only in risky real investment projects, funded by financial claims issued to savers. (We relax this assumption later in section 4.5). We normalize the endowment to $e \equiv 1+S / T$.

There are differences in political risk across regions. The domestic government never expropriates, while the foreign government may seize all assets in its own region, except storage. Hence, foreign investors may satisfy their need for absolute safety only through storage or by investing abroad through domestic intermediaries. Let the chance of expropriation be $\theta_{L}>0$ for foreign investors. Domestic agents investing in foreign assets are more at risk, $\theta_{H}>\theta_{L}$. This difference is large enough to discourage speculative capital flows across regions, which allows us to focus on safety-seeking flows:

\footnotetext{
${ }^{4}$ If direct holdings of domestic assets were allowed, an alternative assumption is that foreign investors need to safe-keep any direct holdings by using storage, which returns only a fraction $x$ of payoffs.
} 


$$
\left(1-\theta_{H}\right) R_{F}<T<\left(1-\theta_{L}\right) R_{F},
$$

where $R_{F}$ is the expected return on risky foreign investment.

Intermediaries are subject to limited liability and maximize the expected value of equity at $t=2$. They have a common risky technology at $t=0$, whose return at $t=2$ is either $R$ (high state) with probability $\gamma \in(0,1)$ or zero (low state) ${ }^{5}$ Investing $I_{i} \geq 0$ by intermediary $i \in[0,1]$ has decreasing returns to scale, where $R^{\prime}\left(I_{i}\right)<0$ and $R^{\prime \prime}\left(I_{i}\right) \leq 0$. Early liquidation at $t=1$ yields a fraction $\alpha \in(0,1)$, so it is efficient in the low state. The liquidation decision at the interim date is not contractible.

If storage were extremely inefficient, $x \leq \alpha$, safety-seeking investors would obtain the required return even in case of early liquidation. In equilibrium, foreign investors would actually provide insurance to domestic investors. To exclude this case, we assume $\alpha<x$.

At $t=1$, a precise signal may reveal the final-date return. The chance of revelation of the high state is $\delta \in(0,1)$, while the chance of revelation of the low state is $1-\epsilon \in(0,1)$. Thus if no signal is received, some residual uncertainty remains. See Figure 2 for a summary.

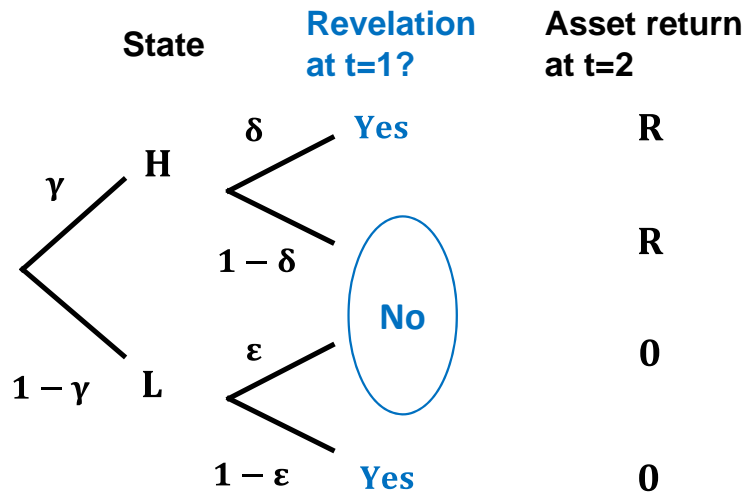

Figure 2: The information structure of domestic risky investment.

\footnotetext{
${ }^{5}$ We consider the case of imperfect correlation of investment returns across intermediaries in section 4.6 .
} 
At $t=0$, intermediaries raise domestic funding, $d_{i} \geq 0$, and foreign funding, $f_{i} \geq 0$, to invest $I_{i}$. Each intermediary has local access to one unit of domestic funding, $d_{i} \leq 1$, and competes freely for foreign funding. We restrict attention to simple debt contracts Hart and Moore, 1998), assuming neither the signal nor the final return are contractible. Each intermediary $i$ offers a menu of debt contracts that may vary in the amount and timing of repayment, the composition of funding and seniority. Pro rata applies when assets are insufficient to repay equally senior claims. For long-term assets to be funded, both long-term and demandable debt are feasible funding contracts, which may specify seniority at the final date. We solve for the optimal contract in this restricted class of contracts.

When debt is demandable, continuation of investment at $t=1$ depends on the rollover behavior of investors. We abstract from runs as result of pure coordination failure Allen and Gale, 1998). The bank may also choose to terminate a project at $t=1$. When the state is known, it is efficient to continue in the high state (since $R>\alpha$ ) and to liquidate in the low state (since $\alpha>0$ ). When there is residual uncertainty, the probability of the good state is $\frac{\gamma(1-\delta)}{\gamma(1-\delta)+(1-\gamma) \epsilon}$. We assume that the NPV of continuation is positive:

$$
\epsilon<\bar{\epsilon} \equiv \frac{\gamma(1-\delta)}{1-\gamma} \frac{R-\alpha}{\alpha}
$$

which holds if the investment return $R$ is large relative to $\alpha$ or the high state is likely.

As a benchmark, consider the portfolio choice under autarky. Foreign investors use storage to satisfy their absolute safety needs and invest any residual wealth in risky foreign investment subject to expropriation risk. Domestic investors satisfy their absolute safety needs by investing $S / T$ in the long-term bond, as it dominates storage. The remaining unit wealth is invested through domestic intermediaries, provided the claim yields at least $T$.

Marginal revenue in the high state decreases in investment, $M R\left(I_{i}\right) \equiv I_{i} R^{\prime}\left(I_{i}\right)+R\left(I_{i}\right)$. As investment is continued under uncertainty, the expected marginal revenue of investment is $\gamma M R(I)+(1-\gamma)(1-\epsilon) \alpha$. Let risky investment initially dominate the long-term bond. 
We assume that domestic funding suffices for the efficient level of investment in autarky:

$$
\gamma M R(0)+(1-\gamma)(1-\epsilon) \alpha>T>\gamma M R(1)+(1-\gamma)(1-\epsilon) \alpha
$$

Autarky investment $I^{\text {Aut }} \in(0,1)$ equalizes the expected marginal revenue of investment with the opportunity cost of funding, $\gamma M R\left(I^{A u t}\right)+(1-\gamma)(1-\epsilon) \alpha=T$. As domestic investors are willing to invest in risky long-term debt, there are never runs at $t=1$. The face value of long-term debt in autarky is independent of the volume of funding, $L_{2} \equiv \frac{T-(1-\gamma)(1-\epsilon) \alpha}{\gamma}$.

\section{Unstable inflows and endogenous risk}

We now study the optimal funding choice by intermediaries when foreign funding is available. As under autarky, domestic investors have a unit wealth available to buy a risky claim from intermediaries for an expected return of $T$. Foreign savers could satisfy their need for safety either by storing an amount $S / x$ or by accepting a safe claim on a domestic intermediary, provided it has a return of at least $x$. Their remaining wealth is channeled to risky foreign investment. We can now state a first result.

Proposition 1 Optimal funding contract of domestic intermediaries. Domestic funding $d_{i}>0$ is attracted with long-term debt $(0, L)$ at an expected cost of $T$. Safetyseeking foreign funding $f_{i} \geq 0$ may be attracted with demandable debt $(x, X)$, provided a sufficient amount of loss-absorbing domestic funding is attracted, $d_{i} \geq \frac{x-\alpha}{\alpha} f_{i}$.

The optimal funding choice is shaped by the demand for absolute safety by foreign investors. Since intermediaries continue investment under residual uncertainty at $t=1$, there is a chance of complete loss if the low state ultimately materializes. Thus foreign investors refuse long-term debt, even if senior, as it does not offer absolute safety. To attract cheap safety-seeking foreign funding, intermediaries must offer a demandable debt 
claim backed up by enough loss-absorbing long-term funding. Foreign investors ensure their absolute safety by withdrawing at the interim date whenever the state is low or uncertain. Withdrawing when the state is low protects their priority relative to long-term debt (no dilution) ${ }^{6}$ Withdrawing when the state is uncertain avoids the chance (however small $\epsilon$ may be) of a complete loss.

Corollary 1 If foreign funding is attracted, there is always some liquidation of investment under residual uncertainty. Such liquidation is ex-post inefficient in the high state. The efficiency loss increases in the scale of foreign funding and the chance of a high state.

The cost of foreign funding is $X_{2}$ when the state is revealed to be high, while due to liquidation it is $\frac{R\left(I_{i}\right)}{\alpha} X_{1}$ in the high state when there is residual uncertainty. Accordingly, in the optimal contract targeted at foreign funding, intermediaries would rather compete by increasing the promised amount at the final date $X_{2} \equiv X$ rather than the early withdrawal value $X_{1}$, to minimize costly liquidation. The promised amount for early withdrawals is thus set as low as consistent with absolute safety, $X_{1}^{*}=x$.

The trade-off associated with foreign funding is therefore a lower funding cost and a higher volume of investment versus excess liquidations in the high state. The intermediary's problem can be reduced to the following (see Appendix B):

$$
\begin{aligned}
\max _{f_{i} \in[0, \infty), d_{i} \in[0,1]} \pi_{i}= & I_{i}\left[\gamma R\left(I_{i}\right)+(1-\gamma)(1-\epsilon) \alpha\right]-d_{i} T \\
& -f_{i}\left[\gamma \delta X+x\left(\gamma(1-\delta) \frac{R\left(I_{i}\right)}{\alpha}+(1-\gamma)(1-\epsilon)\right)\right] \\
\text { s.t. } \quad & x f_{i} \leq \alpha I_{i}=\alpha\left(d_{i}+f_{i}\right),
\end{aligned}
$$

where $\pi_{i}$ is the expected profit of intermediary $i$. We assume there is sufficient domestic funding to ensure that intermediaries are not constrained in their choice of foreign funding. We obtain an interior solution $d_{i}^{*}<1$, provided decreasing returns satisfy

\footnotetext{
${ }^{6}$ If demandable debt was senior at the final date, foreign investors would not withdraw at the interim date. But the allocation is unaffected because intermediaries always liquidate after a low return is revealed.
} 


$$
M R\left(\frac{x}{x-\alpha}\right)<\alpha+\frac{x-\alpha}{x} \frac{T}{\gamma \delta}
$$

Intermediaries attract no foreign funding if interim uncertainty is too high, defined by $\delta \leq \underline{\delta} \in(0,1)$ (see Appendix $B)$.

Lemma 1 Demand for funding. Provided $\delta>\underline{\delta}$, there exists a unique switching threshold, $X_{S}>x$, such that

- if foreign funding is expensive, $X \geq X_{S}$, autarky is optimal: $f_{i}^{*}=0$ and $d_{i}^{*}=I^{\text {Aut }}$;

- if $X_{S}>X \geq x$, both types of funding are attracted, while the safety constraint binds, $d_{i}^{*}=\left(\frac{x-\alpha}{\alpha}\right) f_{i}^{*}$. The demand for foreign funding, $f_{i}^{*}(X)$, is uniquely given by

$$
\gamma \delta M R\left(\frac{x}{\alpha} f_{i}^{*}\right)=T+\frac{\alpha}{x}[\gamma \delta X-T]
$$

We focus on the solution with intermediation of foreign wealth described in Lemma 1 . When foreign funding is attracted, the expected marginal revenue of investment equals the weighted average cost of domestic and foreign funding.

Aggregation of intermediary demand implies $f \equiv \int_{0}^{1} f_{i} d i$. In equilibrium, the amount of foreign wealth determines the amount and cost of demandable debt.

Proposition 2 Unique equilibrium. There exists a unique equilibrium if $\delta>\underline{\delta}$ and there is sufficient foreign wealth, $W>\underline{W}$. For $W \leq \bar{W}$, there exists an interior allocation, with foreign funding, $f_{i}^{*}=f^{*}=\frac{W S}{x}$, and domestic funding, $d_{i}^{*}=d^{*}=\frac{x-\alpha}{\alpha x} W S \in(0,1)$.

We can now assess the risk created by safety-seeking capital inflows.

Proposition 3 Excessive liquidation. When foreign funding is attracted, $W \in(\underline{W}, \bar{W})$, 
withdrawals by safety-seeking foreign investors under interim uncertainty lead to inefficient

liquidation of investment. The resulting efficiency loss in the high state is $\frac{S W}{\alpha}\left[R\left(\frac{S}{\alpha} W\right)-\alpha\right]$.

Finally, the NPV of domestic investment depends on the scale of foreign funding. If the uncertain state is not too frequent, it may be negative at domestic discount rates (for the definition of $\underset{\sim}{\delta}$, see Appendix $\mathrm{D}$.

Proposition 4 Negative $\boldsymbol{N P V}$. For $W \in(\underline{W}, \bar{W})$, the level of domestic investment increases in foreign wealth, while its NPV at domestic discount rates decreases in it. If $\delta>\underset{\sim}{\delta}$, there exists a unique wealth threshold $W^{*} \in(\underline{W}, \bar{W})$ such that the NPV of investment is negative at domestic discount rates for all $W>W^{*}$.

In the basic setup, an expansion in domestic investment is efficient, as insuring foreign investors subsidizes the discount rate for intermediaries.

\section{Extensions}

\subsection{Endogenous uncertainty}

In the basic model, inefficient runs are triggered by interim uncertainty about the asset return. This section studies how more lending may imply investing in more opaque assets, whose value is not riskier but more uncertain at the interim date. Specifically, let $\delta=\delta\left(I_{j}\right)$ be a function of the volume of investment, with $\frac{d \delta}{d I_{j}}<0$.

It is easy to show that higher investment leads to a greater frequency of runs since a precise signal occurs less often in the high state. As the intermediary bears all cost, the impact of more opaque investment is fully internalized and the demand for funding in Lemma 1 generalizes. If foreign funding is cheap, $X<X_{S}^{\delta}$, the intermediary still attracts as much foreign funding as possible, constrained by the absolute safety condition, $f_{i}^{*}=\frac{\alpha}{x-\alpha} d_{i}^{*}$. 
The demand for foreign funding, $f_{i}^{*}(X)$, and the investment level, $I_{i}^{*}(X)=\frac{x}{\alpha} f_{i}^{*}(X)$, solves:

$$
\gamma \delta\left(I_{i}^{*}\right) M R\left(I_{i}^{*}\right)=T+\frac{\alpha}{x}[\gamma \delta\left(I_{i}^{*}\right) X-T \underbrace{-\gamma \delta^{\prime}\left(I_{i}^{*}\right)\left(\frac{x}{\alpha} R\left(I_{i}^{*}\right)-X\right)}_{>0}],
$$

where the last term is positive and captures the effect of more frequent excess liquidation. As residual claimant in the high state, the intermediary internalizes all costs of asset opacity and chooses a lower scale of foreign funding compared to the baseline case.

\subsection{Social cost of excessive liquidation}

Under the optimal contract, intermediaries trade off the cost and stability of foreign funding. Even though it causes some ex-post inefficient liquidation, foreign funding is efficient from an ex-ante perspective. However, a proper welfare analysis must consider the possibility that bank runs have social consequences. A natural case is that excess liquidation imposes social costs associated with early termination, such as spillover losses or social distress. Larger runs may also affect the liquidation price of assets or undermine confidence in domestic intermediaries, causing a negative externality (Stein, 2012).

We introduce a social cost of excess liquidation, $\xi>0$, per unit of assets terminated early in the high state in the extended model with endogenous opacity. Recall that in autarky, there are no such costs because all funding is long-term.

A constrained planner internalizes the social cost of excess liquidation, taking the supply of foreign and domestic funding as well as the absolute safety constraint of foreign investors as given. For sufficiently cheap foreign funding, the social optimum of investment $I_{P}(X)$, and the demand for foreign funding $f_{P}(X)$, have an interior solution as before:

$\gamma \delta\left(I_{P}\right) M R\left(I_{P}\right)=T+\frac{\alpha}{x}\left[\gamma \delta\left(I_{P}\right) X-T-\gamma \delta^{\prime}\left(I_{P}\right)\left(\frac{x}{\alpha} R\left(I_{P}\right)-X\right)\right]+\underbrace{\xi\left[\gamma\left(1-\delta\left(I_{P}\right)\right)-\gamma \frac{x}{\alpha} \delta^{\prime}\left(I_{P}\right) f_{P}\right]}_{>0}$. 
Relative to the private choice, the constrained planner incorporates the social cost of excessive liquidation. The planner's volume of investment is lower and the degree of stability higher. A broader implication is that stable funding norms (proposed by Basel III) should be adjusted to recognize the lower stability associated with safety-seeking foreign inflows.

\subsection{Induced runs}

While more foreign funding can increase both the scale and frequency of runs, so far it has had no effect on the behavior of domestic investors. To study a direct interaction between foreign and domestic funding, we now consider the plausible case when domestic savers hold demandable debt claims for reasons other than safety, such as the ease of payment or timing of liquidity needs. Specifically, suppose an additional mass, $\omega>0$, of domestic investors chooses a demandable debt claim for exogenous reasons. For simplicity, we keep the amount of risk-absorbing domestic funding constant, so the capacity to provide absolute safety is unchanged. This demandable debt claim promises a return of $X^{*}$ at $t=2$ and is as senior as long-term debt with face value $L^{*}$ in case of early liquidation.

As domestic savers are not exposed to expropriation risk and have already secured their safety needs, they would not run in (modest) uncertainty, provided the rollover premium is adequate. Indeed, for a low $\epsilon$, all agents share the belief that the chance of the high state is very high. However, even risk-tolerant domestic savers would choose to withdraw whenever

$$
\frac{\gamma(1-\delta)}{\gamma(1-\delta)+(1-\gamma) \epsilon} \min \left\{X^{*},\left(R\left(I^{*}\right) I^{*}-R\left(I^{*}\right) \frac{x}{\alpha} f^{*}\right) \frac{X^{*}}{\omega X^{*}+L^{*}}\right\} \leq x
$$

where the first factor is the probability of the high state under uncertainty and the second factor is the value of the demandable debt claim in case of a foreign run.

Interestingly, more foreign wealth has several effects on the risk of a run by domestic investors in equilibrium. First, it leads to a lower face value of demandable debt at the final date, $X^{*}$. Second, it implies larger runs under uncertainty and thus more liquidation, 
diluting the return of domestic investors who roll over. Third, more foreign funding leads to more marginal investment returns. All of these effects increase the incentives of domestic savers to withdraw at the interim date under residual uncertainty. An increasing reliance on foreign funding will therefore trigger instability of domestic funding at some point.

The induced run occurs despite the capacity of domestic investors to bear risk and the common belief that the state is very likely to be high. Runs occur to avoid a dilution of the domestic claim caused by a foreign run.

\subsection{Private arbitrage}

In this section, we study whether domestic investors could avoid excess liquidation by becoming arbitrageurs, relying on their superior risk absorption capacity.

This strategy entails transferring some resources to the interim date, which has an opportunity cost of the term premium, $T-1$. Whenever there is uncertainty, arbitrageurs could buy claims from withdrawing foreign investors and then negotiate with the bank to appropriate the gain from avoiding liquidation. Consider the maximum benefit of this strategy, especially when the arbitrageur has all the bargaining power. An arbitrageur with a unit of capital at $t=1$ could then buy $1 / x$ units of demandable claims in case of interim uncertainty and trade them for a long-term claim worth $\frac{R(I)}{\alpha} x$. This strategy generates $\frac{R(I)}{\alpha}$ in the high state, which occurs with an ex-ante probability of $\gamma(1-\delta)$, and a complete loss in the low state. Thus, a sufficient condition to exclude the possibility of domestic arbitrageurs is, for a given amount of investment as follows:

$$
T-1>\gamma(1-\delta) \frac{R\left(I^{*}\right)}{\alpha}
$$

In sum, a private solution to the ex-post inefficiency fails when its opportunity cost, the term premium, exceeds the maximum expected gain. For more general bargaining games, 
or in the presence of specific costs, the condition will be less stringent.

Note that it is impossible for the arbitrageur to increase its expected profits by leverage. Other domestic investors have the same opportunity cost, while foreign investors would not invest because domestic arbitrageurs cannot offer absolute safety.

\subsection{Safe intermediaries}

We have so far restricted domestic intermediaries to invest in risky projects. In this section, intermediaries may also hold bonds. In this case, could safe intermediaries emerge to invest in safe domestic bonds and offer long-term debt to foreign savers? This would allow intermediaries to capture the safety premium without inefficient liquidation driven by runs.

Such an arrangement is fragile in the context of absolute safety needs. We continue to assume that the composition of funding is contractible. However, even a slight chance that the asset choice of such intermediaries cannot be constrained (infinitesimal governance risk) will undermine the credibility of safe intermediaries as sources of absolute safety. We show that safe intermediaries, because of their leverage, will have an incentive to make risky investment. Thus safe intermediaries cannot always commit to investing in safe bonds.

Specifically, suppose that an intermediary raises long-term funding at face value $F \geq x$ from foreign investors. If invested in long-term bonds, the intermediary's riskless profit is $T-F$ per unit of funding $f$, so $\pi(s a f e)=f[T-F]$. However, if the intermediary makes risky investment, foreign investors are repaid in the high state but default occurs in the low state. The expected profit to the intermediary is therefore $\pi(r i s k y)=\gamma f[R(f)-F]$. Risk-taking incentives are lowest for low funding costs, whereby the intermediary attracts cheap funding, $F=x$, and low investment returns as a result of decreasing returns, whereby $f=W$. As a result, a sufficient condition for leveraged intermediaries to prefer risky investment is

$$
\gamma[R(W)-x]>T-x
$$


Intermediaries cannot commit to offering absolute safety, as required to attract foreign funding. Even in the context of the safest class of money market mutual funds, Kacperczyk and Schnabl (2013) document risk-taking behavior during the recent financial crisis.

\subsection{Correlated runs}

So far we have assumed that all investment returns are perfectly correlated, which implies that runs under interim uncertainty create a systemic crisis by assumption. However, safetyseeking demand can easily create correlated runs.

Assume that investment is uncorrelated across intermediaries. Were investors to receive information on each lending pool, runs would occur for all intermediaries with uncertain asset values, as in the baseline case. However, investors are more likely to receive information about aggregate profitability. In principle, this would encourage diversification across intermediaries. Suppose investors learn the fraction of intermediaries for which asset value is uncertain but not which banks are affected. Because of the risk-intolerance of foreign investors, a run on all domestic intermediaries occurs if complete diversification is too costly.

Alternatively, consider the case when investors hold claims on all lending pools, and assume that a positive mass of intermediaries is affected. Systemic runs on all intermediaries

would occur whenever the expected return of continuation (the cross-sectional expected return under full diversification) is smaller than the required return to ensure absolute safety:

$$
\gamma R\left(I^{*}\right)+(1-\gamma)(1-\epsilon) \alpha<x
$$




\section{Conclusion}

This paper has sought a foundation for the widespread view that global imbalances shaped the credit boom and, ultimately, the financial crisis (Caballero and Krishnamurthy, 2009). We show how the accumulation of wealth in countries with a weak protection of property rights creates a demand for absolute safety provided by intermediaries in developed countries. The optimal contractual arrangement shapes the funding structure of domestic intermediaries, creating a clear link between inexpensive funding, credit expansion and instability.

Studying inflows into developed countries is specular to the literature on sudden capital outflows from emerging economies. Our contribution is to derive the optimal funding arrangement shaped by a demand for safety and to show how it may create endogenous fragility. In our model, domestic and foreign investors have identical preferences and endowments, but regions differ in their exposure to expropriation risk. The optimal funding arrangement comprises loss-absorbing and long-term claims issues to domestic investors and demandable debt claims issued to foreign investors. Demandable debt offers safety at the expense of greater fragility, making foreign funding cheap but flighty.

While global imbalances reflect major shifts in wealth away from developed countries, a large fraction has flown back in the form of inexpensive claims on domestic intermediaries, allowing developed countries to expand credit at times of declining savings. We show that the safety-seeking nature of foreign flows creates risk. The demand for absolute safety not only redistributes risk among investors, but it also increases risk through larger and more frequent runs. The funding shift leads to greater vulnerability even in solvent states and may induce further runs by risk-tolerant investors who seek to avoid dilution. This result has clear implications and supports a mandate for implementing macroprudential policy to oversee the nature of foreign inflows, since the socially preferred funding structure would involve less credit volume and lower instability than the private choice. 


\section{References}

Allen, F., E. Carletti, and R. Marquez (2015). Deposits and Bank Capital Structure. Journal of Financial Economics.

Allen, F. and D. Gale (1998). Optimal Financial Crises. Journal of Finance 53(4), 12451284.

Badarinza, C. and T. Ramadorai (2015). Home Away From Home? Foreign Demand and London House Prices. Mimeo.

Bernanke, B. S. (2005). Remarks by Governor Ben S. Bernanke on 10 March 2005. Sandridge Lecture, Virginia Association of Economists, Richmond, Virginia.

Caballero, R. and E. Farhi (2013). A Model of the Safe Asset Mechanism (SAM): Safety Traps and Economic Policy. Mimeo.

Caballero, R. J., E. Farhi, and P. O. Gourinchas (2008). An Equilibrium Model of "Global Imbalances" and Low Interest Rates. American Economic Review 98(1), 358-93.

Caballero, R. J. and A. Krishnamurthy (2009). Global Imbalances and Financial Fragility. American Economic Review 99(2), 584-88.

Calomiris, C. W. and C. M. Kahn (1991). The Role of Demandable Debt in Structuring Optimal Banking Arrangements. American Economic Review 81(3), 497-513.

Campbell, J. Y. and J. Cochrane (1999). By Force of Habit: A Consumption-Based Explanation of Aggregate Stock Market Behavior. Journal of Political Economy 107(2), $205-51$.

Diamond, D. and P. Dybvig (1983). Bank Runs, Deposit Insurance and Liquidity. Journal of Political Economy 91, 401-419.

Diamond, D. and R. G. Rajan (2001). Liquidity Risk, Liquidity Creation, and Financial Fragility: A Theory of Banking. Journal of Political Economy 109(2), 287-327. 
Forbes, K. J. (2010). Why do Foreigners Invest in the United States? Journal of International Economics 80(1), 3-21.

Gennaioli, N., A. Shleifer, and R. Vishny (2013). A Model of Shadow Banking. Journal of Finance 68(4), 1331-63.

Gorton, G., S. Lewellen, and A. Metrick (2012). The Safe-Asset Share. NBER Working Paper No. 17777.

Gorton, G. and G. Pennacchi (1990). Financial Intermediaries and Liquidity Creation. Journal of Finance 45(1), 49-71.

Gourinchas, P.-O. and H. Rey (2007). From World Banker to World Venture Capitalist: US External Adjustment and the Exorbitant Privilege. In G7 Current Account Imbalances: Sustainability and Adjustment, pp. 11-66. University of Chicago Press.

Gourinchas, P.-O., H. Rey, and N. Govillot (2010). Exorbitant Privilege and Exorbitant Duty. Institute for Monetary and Economic Studies Discussion Paper 10-E-20.

Hahm, J.-H., H. Shin, and K. Shin (2013). Non-Core Bank Liabilities and Financial Vulnerability. Journal of Money, Credit and Banking 45, 3-36.

Hart, O. and J. Moore (1998). Default and Renegotiation: A Dynamic Model of Debt. Quarterly Journal of Economics 93(1), 1-41.

Jorda, O., M. H. Schularick, and A. M. Taylor (2014). Betting the House. Working Paper 20771, National Bureau of Economic Research.

Kacperczyk, M. and P. Schnabl (2013). How Safe Are Money Market Funds? Quarterly Journal of Economics 128(3), 1073-1122.

Krishnamurthy, A. and A. Vissing-Jorgensen (2012). The Aggregate Demand for Treasury Debt. Journal of Political Economy 120(2), 233-267.

Krishnamurthy, A. and A. Vissing-Jorgensen (2013). Short-term Debt and Financial Crises: What We Can Learn From U.S. Treasury Supply. Mimeo. 
Lucas, Robert E, J. (1990). Why Doesn't Capital Flow from Rich to Poor Countries? American Economic Review 80(2), 92-96.

Maggiori, M. (2013). The U.S. Dollar Safety Premium. Mimeo.

Mendoza, E., V. Quadrini, and J.-V. Rios-Rull (2009). Financial Integration, Financial Development, and Global Imbalances. Journal of Political Economy 117(3), 371-416.

Merrouche, O. and E. Nier (2014). The Global Financial Crisis - What Drove The BuildUp? Centre for Economic Policy Research Discussion Paper 10015.

Perotti, E. and J. Suarez (2011). A Pigovian Approach to Liquidity Regulation. International Journal of Central Banking 7(4), 3-41.

Prasad, E. S., R. G. Rajan, and A. Subramanian (2007). Foreign Capital and Economic Growth. Brookings Papers on Economic Activity 38(1), 153-230.

Quadrini, V. (2015). The Growth of Emerging Economies and Global Macroeconomic Stability. Mimeo.

Shin, H. S. (2011). Global Banking Glut and Loan Risk Premium. 2011 Mundell-Fleming Lecture.

Stein, J. (2012). Monetary Policy as Financial-Stability Regulation. Quarterly Journal of Economics 127(1), 57-95. 


\section{Appendix A Proof of Proposition 1}

We start with the optimal portfolio choice of investors. Let $\left(X_{1}, X_{2}\right)$ be the claim targeted at foreign investors and $\left(L_{1}, L_{2}\right)$ be the claim targeted at domestic investors.

Claim 1 Portfolio choice of domestic investors. If the return on the absolutely safe claim $\left(X_{1}, X_{2}\right)$ does not exceed $T$, domestic investors satisfy their absolute safety need by investing $S / T$ in the domestic long-term bond. The remaining unit wealth is supplied to a domestic intermediary if the claim $\left(L_{1}, L_{2}\right)$ has an expected return of at least $T$.

Proof For the absolute safety component of the portfolio of domestic investors, the domestic long-term bond dominates both storage and the domestic short-term bond. Investment in foreign assets does not yield absolute safety because of expropriation risk. Therefore, domestic investors satisfy their absolute safety needs by investing $S / T$ in long-term domestic bond. While investing in a safe claim issued by a domestic intermediary could also ensure absolute safety, it would yield a lower return. For the speculative component of the portfolio of domestic investors, all foreign assets are dominated because of expropriation risk. Thus, domestic investors either invest in (more of) the domestic long-term bond or in a risky claim issued by a domestic intermediary.

Claim 2 Portfolio choice of foreign investors. To satisfy their absolute safety needs, foreign investors accept a claim issued by a domestic intermediary if it is absolutely safe and has a return of at least $x$. Their remaining wealth is channeled to foreign risky investment if the risky claim issued by an intermediary does not reach the expropriation-adjusted expected return of $\left(1-\theta_{L}\right) R_{F}$.

Proof Consider the absolute safety component of the portfolio of foreign investors. Foreign bonds and foreign risky investment do not provide absolute safety because of expropriation risk. As a result, either storage or an absolutely safe claim issued by a domestic intermediary 
generates the required absolute safety. For foreign savers to accept such the latter claim, it would need to yield a return of at least $x$. For the speculative component of the portfolio of foreign investors, risky foreign investment dominates other foreign and domestic assets. Provided that a claim offered by a domestic intermediary does not offer at least $\left(1-\theta_{L}\right) R_{F}$, all residual wealth is invested in risky foreign investment.

Foreign savers would need to invest $\frac{S}{x}$ in storage to achieve absolute safety. If a demandable debt claim $(x, X)$ is absolutely safe, then it faces an aggregate demand of

$$
f(X)=\left\{\begin{array}{lll}
{\left[0, \frac{W S}{x}\right]} & & X=x \\
\frac{W S}{x} & \text { if } & \\
& & X>x
\end{array}\right.
$$

Next, we turn to the claims that would be accepted from a domestic intermediary by foreign investors who seek absolute safety. We consider long-term debt and demandable debt in turn.

Claim 3 Long-term debt. Foreign investors never accept any long-term debt claim.

Proof Consider a long-term debt claim $\left(X_{1}=0, X_{2} \geq x\right)$ where the inequality ensures a return no smaller than that of storage. Under which conditions would this claim be absolutely safe? First, if the state is revealed to be low, absolute safety requires seniority of foreign investors (to avoid the dilution of their claim relative to domestic investors) and a sufficient amount of loss-absorbing domestic funding, $\alpha I_{i} \geq x f_{i}$.

Second, consider the case of residual uncertainty at $t=1$, when no signal is received. Recall that investment efficiently continues in the high state, $R(I)>\alpha$ and that the continuation of investment is optimal, $\epsilon<\bar{\epsilon} \equiv \frac{\gamma(1-\delta)}{1-\gamma} \frac{R(I)-\alpha}{\alpha}$. As a result, a complete loss occurs if the state is low at $t=2$. However, this violates a foreign investor's need for absolute safety. 
A foreign investor would therefore never accept a long-term debt claim, not even a senior claim.

Claim 4 Absolute safety and demandable debt. Foreign investors accept a demandable debt claim if enough (loss-absorbing) long-term funding is attracted. This requires $d_{i} \geq$ $\frac{x-\alpha}{\alpha} f_{i}$ when domestic investors hold long-term debt, $L_{1}=0$. Foreign investors can ensure absolute safety by withdrawing at $t=1$ under residual uncertainty. To avoid dilution, foreign investors also withdraw when the signal reveals the state to be low if $L_{2} \geq X_{2}$.

Proof Consider a demandable debt claim $\left(X_{2} \geq X_{1} \geq x\right)$, where the first inequality ensures that foreign investors do not withdraw when the state is revealed to be high. To ensure absolute safety under residual uncertainty, foreign investors must withdraw to avoid a complete loss at $t=1$. Absolute safety is assured under residual uncertainty, provided that enough domestic funding is attracted, $\alpha I_{i} \geq x f_{i}$, and that such funding is loss-absorbing; in other words, domestic investors do not withdraw at $t=1$. Long-term debt issued to domestic investors would avoid dilution of a foreign investor's claim at $t=1$ under residual uncertainty. Moreover, foreign investors withdraw at $t=1$ when the signal reveals the state to be low so they can avoid dilution at $t=2$. Their claim at $t=2$ does not guarantee absolute safety when $X_{2} \frac{\alpha I_{i}}{X_{2} f_{i}+L_{2} d_{i}}<x$, where we used pro-rata in default. Since $\alpha<x$, this condition holds for any positive amount of funding if $L_{2} \geq X_{2}$.

We now turn to the funding and portfolio choices of domestic intermediaries.

Lemma 2 Domestic intermediaries do not offer a claim that yields more than $T$ in expectation and do not make any foreign investments.

Proof Domestic funding can be attracted locally with a long-term debt claim that yields $T$ in expectation. Because of decreasing returns to scale, and since the efficient level of investment when the expected funding cost is $T$ can be reached by attracting domestic 
funding only, there is no reason to attract foreign funding at a higher cost. This applies to both absolutely safe and risky claims.

Domestic investors do not invest abroad. Foreign bonds are dominated by domestic bonds because of expropriation risk. The proof is by contradiction. Suppose that a domestic intermediary invested in foreign risky investment. Since a domestic intermediary is subject to expropriation risk in the foreign region, such investment yields a zero return with positive probability and cannot support absolute safety offered to foreign investors. Moreover, it yields an expropriation-adjusted return of $\left(1-\theta_{H}\right) R_{F}<T$, below the required return of domestic investors.

As a result, the absolutely safe claim must yield less than the risky claim, $X_{2} \leq L_{2}$. Also, foreign investors, if their funding is attracted, always withdraw when the state is revealed to be low (Claim 4). Moreover, foreign investors never invest in domestic intermediaries for speculative purposes (Claim 2). Taking these results together, we obtain at the optimal funding contract stated.

\section{Appendix B Proof of Lemma 1}

We start by showing that the bank's problem simplifies as stated. Table 1 summarizes all payoffs when foreign funding is attracted. We compare the expected equity value when foreign funding is attracted and in autarky at the end.

\begin{tabular}{|l|l|l|l|l|l|}
\hline state & probability & liquidate? & $\pi_{F}$ & $\pi_{D}$ & $\pi_{i}$ \\
\hline$H$ & $\gamma \delta$ & None & $X$ & $L$ & $R I_{i}-L d_{i}-X f_{i}$ \\
$H$ & $\gamma(1-\delta)$ & Some & $x$ & $\min \left\{L, R \frac{I_{i}-\frac{x}{\alpha} f_{i}}{d_{i}}\right\}$ & $\max \left\{0, R\left(I_{i}-\frac{x}{\alpha} f_{i}\right)-L d_{i}\right\}$ \\
$L$ & $(1-\gamma) \epsilon$ & Some & $x$ & 0 & 0 \\
$L$ & $(1-\gamma)(1-\epsilon)$ & Full & $x$ & $\frac{\alpha I_{i}-x f_{i}}{d_{i}}$ & 0 \\
\hline
\end{tabular}

Table 1: Payoffs when foreign capital is attracted. $\pi_{D}$ and $\pi_{F}$ are the payoffs to domestic and foreign investors, respectively, while $\pi_{i}$ is the payoff to intermediary $i$. 
The participation constraint of domestic investors is as follows:

$$
\mathbb{E}\left[\pi_{D}\right]=\gamma \delta L+\gamma(1-\delta) \min \left\{L, \frac{R\left(I_{i}\right) I_{i}-\frac{R\left(I_{i}\right)}{\alpha} x f_{i}}{d_{i}}\right\}+(1-\gamma)(1-\epsilon) \frac{\alpha I_{i}-x f_{i}}{d_{i}} \geq T
$$

Equity is valueless in the low state, so the expected equity value of intermediary $i$ is

$$
\mathbb{E}\left[\pi_{i}\right]=\gamma \delta\left[R\left(I_{i}\right) I_{i}-L d_{i}-X f_{i}\right]+\gamma(1-\delta)\left[\max \left\{R\left(I_{i}\right) I_{i}-\frac{R\left(I_{i}\right)}{\alpha} x f_{i}-L d_{i}, 0\right\}\right]
$$

Each intermediary $i$ maximizes its expected equity value by choosing its funding profile $\left(d_{i}, f_{i}\right)$ and the face value of long-term debt $L$, taking the face value of demandable debt $X$ as given. These choices are restricted by the participation constraint of domestic investors and the absolute safety constraint. The face value of long-term debt reduces the bank's expected profits but makes the participation constraint of domestic investors less binding (without affecting the absolute safety constraint). The bank therefore sets $L$ for the participation constraint of domestic investors to bind. Inserting yields the problem stated in the main text.

We now solve this constrained optimization problem. Let $\mathcal{L}_{i}$ be the Lagrangian of the problem and $\lambda_{i}$ be the Lagrange multiplier associated with the absolute safety constraint of bank $i$. The first-order conditions are as follows:

$$
\begin{aligned}
& \frac{d \mathcal{L}_{i}}{d d_{i}}=\gamma M R\left(I_{i}\right)+(1-\gamma)(1-\epsilon) \alpha-T-\gamma(1-\delta) \frac{x}{\alpha} R^{\prime}\left(I_{i}\right) f_{i}+\lambda_{i} \\
& \frac{d \mathcal{L}_{i}}{d f_{i}}=\gamma M R\left(I_{i}\right)+(1-\gamma)(1-\epsilon)(\alpha-x)-\gamma \delta X-\gamma(1-\delta) \frac{x}{\alpha}\left[R^{\prime} f_{i}+R\right]-\left(\frac{x}{\alpha}-1\right) \lambda_{i}
\end{aligned}
$$

and $\lambda_{i} \geq 0$ and $d_{i} \geq \frac{x-\alpha}{\alpha} f_{i}$ with complementary slackness.

Slack absolute safety constraint Consider the case in which the constraint to provide absolute safety does not bind, $\lambda_{i}^{*}=0$. There are two subcases: (A) foreign funding is more expensive and (B) foreign funding is cheaper than domestic funding. 
(A) more expensive foreign funding Suppose that foreign funding is expensive relative to domestic funding, $X \geq \frac{T}{\gamma \delta}-\frac{(1-\gamma)(1-\epsilon)}{\gamma \delta} x-\frac{1-\delta}{\delta} \frac{x}{\alpha} R\left(I_{i}^{*}\right)$. Then, no foreign funding is attracted, $f_{i}^{*}=0$, and the autarky level of investment occurs, $d_{i}^{*}=I^{\text {Aut }}$. The profit level is $\pi^{\text {Aut }} \equiv I^{\text {Aut }}\left[\gamma R\left(I^{\text {Aut }}\right)+(1-\gamma)(1-\epsilon) \alpha-T\right]$.

We need to confirm two suppositions. First, the absolute safety constraint is trivially slack, $\lambda_{i}^{*}=0$. Second, for foreign funding to be (prohibitively) expensive, we require

$$
X \geq \bar{X} \equiv \frac{T}{\gamma \delta}-\frac{(1-\gamma)(1-\epsilon)}{\gamma \delta} x-\frac{1-\delta}{\delta} \frac{x}{\alpha} R\left(I^{A u t}\right)
$$

Autarky is the unique equilibrium if $\bar{X} \leq x$. However, we impose a lower bound on interim uncertainty to allow for an equilibrium in which foreign funding is attracted:

$$
\delta>\underline{\delta}_{0} \equiv \frac{\gamma R\left(I^{\text {Aut }}\right)+(1-\gamma)(1-\epsilon) \alpha-\frac{\alpha}{x} T}{\gamma\left[R\left(I^{\text {Aut }}\right)-\alpha\right]} \in(0,1)
$$

(B) foreign funding is cheaper than domestic funding If foreign funding is cheap relative to domestic funding, $X<\frac{T}{\gamma \delta}-\frac{(1-\gamma)(1-\epsilon)}{\gamma \delta} x-\frac{1-\delta}{\delta} \frac{x}{\alpha} R\left(I_{i}^{*}\right)$, the intermediary would wish to attract only foreign funding, $f_{i}^{*}>0$, and no domestic funding, $d_{i}^{*}=0$. This allocation violates the absolute safety constraint, however. We have shown by contradiction that when the absolute safety constraint is slack, foreign funding cannot be cheaper than domestic funding.

Binding absolute safety constraint Consider now the case in which the constraint to provide absolute safety binds $\left(\lambda_{i}^{*}>0\right)$. Hence, $d_{i}^{*}=\left(\frac{x}{\alpha}-1\right) f_{i}^{*}$ and $I_{i}^{*}=\frac{x}{\alpha} f_{i}^{*}$. Optimality requires $f_{i}^{*}>0$, so we have $\frac{d \mathcal{L}_{i}}{d f_{i}}=0$. Solving for the Lagrange multiplier yields the following:

$$
\lambda_{i}=\frac{\alpha}{x-\alpha} \gamma M R\left(I_{i}^{*}\right)-(1-\gamma)(1-\epsilon) \alpha-\frac{\alpha \gamma \delta}{x-\alpha} X-\gamma(1-\delta) \frac{x}{x-\alpha}\left[R\left(I_{i}^{*}\right)+R^{\prime}\left(I_{i}^{*}\right) f_{i}^{*}\right]
$$


Inserting the multiplier in $\frac{d \mathcal{L}_{i}}{d d_{i}}$ yields:

$$
\frac{d \mathcal{L}_{i}}{d d_{i}}=\gamma \delta \frac{x}{x-\alpha} M R\left(\frac{x}{\alpha} f_{i}^{*}\right)-T-\gamma \delta \frac{\alpha}{x-\alpha} X
$$

First, if $d_{i}^{*} \in(0,1)$, then $\frac{d \mathcal{L}_{i}}{d d_{i}}=0$, so the optimal amount of foreign (and domestic) funding is implicitly defined by

$$
M R\left(\frac{x}{\alpha} f_{i}^{*}\right)=\frac{x-\alpha}{x} \frac{T}{\gamma \delta}+\frac{\alpha}{x} X
$$

The left-hand side strictly decreases in the amount of foreign funding since $M R^{\prime}(\cdot)<0$. The right-hand side is a positive constant. Note that the left-hand side at zero strictly exceeds the right-hand side for all $X \leq \bar{X}$. Therefore, there exists a unique interior solution $f_{i}^{*}(X)>0$ for all $X<\bar{X}$. That is, $R(0) \geq \frac{x-\alpha}{x} \frac{T}{\gamma \delta}+\frac{\alpha}{x} X$ for all $X \leq \bar{X}$ because of the first boundary condition and the definition of the autarky investment level. The demand for foreign funding is downward-sloping, $\frac{d f_{i}^{*}(X)}{d X}<0$, since the right-hand side increases in the price of foreign funding.

To ensure an interior solution, $d_{i}^{*}<1$, and thus $I_{i}^{*}<\frac{x}{x-\alpha}$, we require sufficiently strong decreasing return when foreign funding is as cheap as possible $(X=x)$ :

$$
\operatorname{MR}\left(\frac{x}{x-\alpha}\right)<\frac{x-\alpha}{x} \frac{T}{\gamma \delta}+\alpha
$$

Finally, one can show that $\lambda_{i}^{*}>0$ always holds, which confirms our initial supposition.

When is autarky optimal? Next, we compare the expected equity value under autarky to the case in which foreign funding is attracted. This allows us to determine the intermediary's globally optimal amount of foreign funding.

The expected equity value of the intermediary that chooses autarky is as follows:

$$
\pi^{A u t} \equiv I^{A u t}\left[\gamma R\left(I^{A u t}\right)+(1-\gamma)(1-\epsilon) \alpha-T\right]
$$


For $X \in[x, \infty)$, a bank's expected equity if choosing to attract foreign funding is

$$
\pi_{i}^{*}(X)=\frac{x}{\alpha} f_{i}^{*}(X)\left[\gamma \delta R\left(\frac{x}{\alpha} f_{i}^{*}(X)\right)-\gamma \delta \frac{\alpha}{x} X-T \frac{x-\alpha}{x}\right]
$$

where $f_{i}^{*}(X) \in\left(0, \frac{\alpha}{x-\alpha}\right)$ and $I_{i}^{*}(X)=\frac{x}{\alpha} f_{i}^{*}(X)$. By the envelope theorem, the expected profit strictly decreases in the face value of foreign funding, $\frac{d \pi_{i}^{*}}{d X}<0$.

Thus, for any foreign funding to be attracted in equilibrium, we require $\pi^{A u t}<\pi_{i}^{*}(x)$, which places a lower bound on interim uncertainty:

$$
\delta>\underline{\delta}_{1} \equiv \frac{-\left(I^{A u t}\right)^{2} R^{\prime}\left(I^{A u t}\right)}{-I_{i}^{*}(x)^{2} R^{\prime}\left(I_{i}^{*}(x)\right)}
$$

Then, the effective lower bound is $\underline{\delta} \equiv \max \left\{\underline{\delta}_{0}, \underline{\delta}_{1}\right\}$.

Under this boundary condition, there exists a unique switching threshold, $X_{S}>x$, such that foreign funding is attracted if, and only if, it is sufficiently cheap, $X<X_{S}$. This threshold is implicitly determined by $\pi^{A u t} \equiv \pi_{i}^{*}\left(X_{S}\right)$.

\section{Appendix C Proof of Proposition 2}

This proof builds on the supply of foreign funding in (13) and Lemma 1. To ensure existence of equilibrium with foreign capital intermediation, we require a lower bound on foreign wealth. This lower bound $\underline{W}$ is given by the interaction between the supply of foreign funding, $f=\frac{W S}{x}$, and the demand for foreign funding, as implied by the solution to the intermediary's problem stated in Lemma 1. Thus, the lower bound on the level of foreign wealth is given by

$$
\gamma \delta M R\left(\frac{S}{\alpha} \underline{W}\right)=\frac{\alpha}{x} \gamma \delta X_{S}+\frac{x-\alpha}{x} T .
$$

Finally, the upper bound on the level of foreign wealth ensures that all foreign wealth is absorbed by domestic intermediaries: 


$$
\gamma \delta M R\left(\frac{S}{\alpha} \bar{W}\right)=\frac{x-\alpha}{x} T+\alpha \gamma \delta
$$

\section{Appendix D Proof of Proposition 3}

This proof builds on the supply of foreign funding in $(13)$, Lemma 1 and Proposition 2 . Foreign funding is attracted whenever foreign wealth is sufficiently abundant, where $W \in$ $(\underline{W}, \bar{W})$. In this equilibrium, the absolute safety constraint binds, $\alpha I_{i}^{*}=x f_{i}^{*}$ for each intermediary $i$. Hence, there are no resources left after foreign investors withdraw at the interim date under uncertainty, and bank equity value is zero in this contingency. Then, the

total efficiency loss is $\left(\frac{R\left(I^{*}\right)}{\alpha}-1\right) x f^{*}$. For $W \in(\underline{W}, \bar{W})$, we establish that $I^{*}=\frac{S}{\alpha} W$ and $f^{*}=\frac{S}{x} W$. Thus, the efficiency loss of $\left(R\left(\frac{S}{\alpha} W\right)-\alpha\right) \frac{S}{\alpha} W$.

\section{Appendix E Proof of Proposition 4}

The NPV of investment at domestic discount rates for a level of foreign wealth $W \in(\underline{W}, \bar{W})$ is

$$
N P V=\frac{\gamma R\left(\frac{W S}{\alpha}\right)+(1-\gamma)(1-\epsilon) \alpha}{T}-1
$$

Hence, the NPV decreases in foreign wealth, $\frac{d N P V}{d W}=\frac{\gamma R^{\prime}\left(\frac{W S}{\alpha}\right) \frac{S}{\alpha}}{T}<0$. By continuity and monotonicity, it suffices to show that the NPV at domestic discount rates, when evaluated at the maximum level of foreign wealth $\bar{W}$, is negative. This condition can be written as $\gamma R\left(\frac{W S}{\alpha}\right)+(1-\gamma)(1-\epsilon) \alpha<T$. Using the definition of $\bar{W}$ and rewriting yields a lower bound as sufficient condition:

$$
\delta>\underset{\sim}{\delta} \equiv \frac{\alpha}{x-\alpha} \frac{T-\alpha[1-(1-\gamma) \epsilon]+\gamma\left(\frac{\bar{W} S}{\alpha}\right) R^{\prime}\left(\frac{\bar{W} S}{\alpha}\right)}{T} .
$$

